\title{
Self-Perception of Iranian Patients during their life with Irritable Bowel Syndrome: A Qualitative Study
}

\author{
Zinat Mohebbi ${ }^{1}$, Farkhondeh Sharif ${ }^{2}$, Hamid Peyrovi ${ }^{3}$, Mahnaz Rakhshan $^{4}$, Mahvash Alizade Naini ${ }^{5}$, Ladan
} Zarshenas $^{6}$

\begin{abstract}
${ }^{1}$ Ph.D. Candidate of Nursing, Faculty Member, Student Research Committee, Department of Medical Surgical Nursing, School of Nursing and Midwifery, Shiraz University of Medical Sciences, Shiraz, Iran

${ }^{2}$ Ph.D. of Psychiatric Nursing, Professor, Community Based Psychiatric Care Research Center, Shiraz Geriatric Research Center, Department of Mental Health and Psychiatric Nursing, School of Nursing and Midwifery, Shiraz University of Medical Sciences, Shiraz, Iran

${ }^{3}$ Ph.D. of Nursing, Professor, Nursing Care Research Center, Iran University of Medical Sciences, Tehran, Iran

${ }^{4}$ Ph.D. of Nursing, Assistant Professor, Department of Medical Surgical Nursing, School of Nursing and Midwifery, Shiraz University of Medical Sciences, Shiraz, Iran

${ }^{5}$ Gastroenterologist, Associate Professor, Gastroenterology and Hepatology Research Center, Department of Gastroenterology and Hepatology, Shiraz University of Medical Sciences, Shiraz, Iran

${ }^{6} \mathrm{Ph} . \mathrm{D}$. of Nursing, Assistant Professor, Community Based Psychiatric Care Research Center, Department of Mental Health and Psychiatric Nursing, School of Nursing and Midwifery, Shiraz University of Medical Sciences, Shiraz, Iran
\end{abstract}

\section{Type of article: Original}

\begin{abstract}
Background: Irritable bowel syndrome (IBS), as a chronic digestive disorder, impacts extensively on the quality of life, emotional well-being and self-identity. Chronic illness disrupts taken-for-granted notions about self. No qualitative study was found regarding patients' experience of life with irritable bowel syndrome (IBS) in Iran.

Objective: To explore the self-perception of lived experience of IBS patients.

Methods: A qualitative study with hermeneutic phenomenological approach was conducted on 12 IBS patients who had been referred to three central clinics ( 2 governmental and 1 private) affiliated to Shiraz University of Medical Sciences. The data were collected through in-depth semi-structured interviews from July 2015 to September 2016 by purposeful sampling. Thematic analysis was carried out using Van Manen's six-step methodological framework as a guide. In addition, MAXQDA software was used for data management.

Results: In this study, two main themes "the threatened self" and "deep self-knowledge", emerged during the life of patients with IBS, indicating the meaning of self-perception of such patients. The theme of "the threatened self" consisted of two subthemes of "fear from stigmatization" and "bad sense of self". The subthemes of "body knowledge", "self-acceptance" and "personal growth" were related to deep self-knowledge.

Conclusion: The results of the present study could be applied in designing and implementation effective and holistic care of IBS patients.

Keywords: Irritable Bowel Syndrome, Self-perception, Qualitative research, Hermeneutic Phenomenology
\end{abstract}

\section{Introduction}

Functional gastrointestinal disorder (FGID) with unexplained etiology and significant adverse effects on patients' health would be difficult to treat. Irritable bowel syndrome (IBS) is the most common among such disorders which is diagnosed by change in intestinal habits and abdominal discomfort (1-3). The prevalence of this syndrome in Western countries is $10.0-22.0 \%(4,5)$ and it has been reported to be $1.1-25.0 \%$ in Iran $(6)$. A study in Shiraz in adults over 35 years old showed that, 10.9\% of them were suffering from IBS (7). According the Rome Foundation,

\section{Corresponding author:}

Professor Dr. Farkhondeh Sharif, Community Based Psychiatric Care Research Center, Shiraz Geriatric Research Center, Department of Mental Health and Psychiatric Nursing, School of Nursing and Midwifery, Shiraz University of Medical Sciences, Shiraz, Iran. Tel: +98.7136474251, Fax:+98.7136474257, Email: fsharif@sums.ac.ir Received: February 14, 2017, Accepted: July 04, 2017, Published: December 2017 iThenticate screening: July 04, 2017, English editing: October 02, 2017, Quality control: November 15, 2017 (C) 2017 The Authors. This is an open access article under the terms of the Creative Commons Attribution-NonCommercialNoDerivs License, which permits use and distribution in any medium, provided the original work is properly cited, the use is non-commercial and no modifications or adaptations are made. 
the prevalence of IBS is significantly less in Asian adults compared with North and Latin American adults (8). This disorder is also considered as one of the common psychosomatic disorders (9). Most patients do not have psychological disorder, but posses some problems of psychological symptoms along with physical symptoms (10). This syndrome is accompanied with psychological comorbidities such as depression, anxiety and somatoform disorders (11-14). Patients with IBS reported a weak quality of life (14-20). Most of them experience absenteeism about three times more than normal people $(17,21)$. This disorder can affect various parts of life, particularly sleep, occupation, sexual function, recreation and travel (21), and involves the psychological, physiological and social environment of the individual (22). Research indicates that self-esteem among healthy individuals is higher than those who live with IBS (23). IBS puts significant pressure on health care resources $(24,25)$. Riddle et al., according to Nellesen et al., said that the direct and indirect medical expenses related to IBS was $\$ 1,562-\$ 7,547$ and $\$ 791-$ $\$ 7,737$ respectively per patient per year $(26,27)$. Moghimi Dehkordi et al. estimated the total 6-month cost of Iranian IBS patients to be about PPP\$160 (purchasing power parity dollars). IBS patients had the highest percentage of drug consumption and the duration of their absenteeism was higher (2.26 days) in comparison with other FGID patients (28). IBS patients account for 30\%-50\% of office visits at gastroenterology services (24, 29). Quantitative studies with positivism paradigm regarding recommendations of life style, educational interventions, dietary adjustments and eating habits and also psychological interventions for such patients have improved some aspects of the effect of this disorder on the life of sufferers to some extent (30-36). On the other hand, chronic illness disrupts taken-for-granted notions like thinking, feeling and acting as well as daily habits that support one's self (37). Theoreticians believe that full recognition of an individual or even predicting his/her behavior will be impossible without understanding the framework of self and its internal criteria. Attaining this objective requires unifying with the conceptual world of the individual and his/her points of view from self. Therefore, understanding the patients' experiences is one of the necessary components of all care (38). Central to Rogers' theory is the notion of self or self-concept. "Self" contains all thoughts, perceptions and values which form "I". "I" contains whatever I am and whatever I can do. This perceived selfhood, in turn, affects the individual's perception of the world as well as his/her behavior (39). A person's self-perception is defined by a person's self-concept, self-knowledge, self-esteem, and social self (40). Bhattacharjee, according to Franken, said that self-concept is the way individuals think about themselves. It is unique, dynamic, and almost evolving. As a global perception of oneself, self-concept shapes and defines who we are, the decisions we develop, and the communications we make $(41,42)$. In nursing, while holistic and efficient care of patients with IBS and their experience is very important, all dimensions of this unique and equivocal phenomenon (living with IBS) are only diagnosed in depth by carrying out qualitative research with naturalism paradigm. Some qualitative research carried out in this regard in Iran, achieved the themes of healing but not curing and taking control of daily life (43), unpredictability and taboos of IBS (44), struggling with an unfamiliar and unreliable body (45) and a feeling of being held hostage (46). Another study in this respect reported the themes of feeling fear and embarrassment, restrictions on social activities/relationships and stigma caused due to lack of understanding by others (47). None of the mentioned studies have pointed out the main theme of patients' self-perception. The results of studies carried out indicate that nurses should observe the experiences from the view of patients so as to help them to resolve their concerns and disabilities (48). To investigate lived experience, making contact with the main experience is necessary (49). Due to uncertainty of various dimensions of IBS, some researchers have recommended that the studying of those patients' perceptions can help care providers to take care of them (50). On the other hand, cultural factors form the person's self-perception and also specify the point of views attributed to chronic diseases and their meanings in a cultural context (51). In various data bases, no qualitative study regarding patients' experience of life with IBS in Iran was found. Some qualitative researchers from other countries have suggested repeated research to be carried out regarding the experience of such patients among various cultural groups (44). When a researcher as an instructor, and a nurse have had the experience of caring for IBS patients and have carried out quantitative research (clinical trials) on them, they can become interested in understanding the nature of living with IBS. Therefore, a research was carried out with the aim to explore the experience of patients from life with IBS. This article focuses on the self-perception of lived experience of these patients which is a large part of the results of the mentioned research. It is hoped that using the obtained knowledge at the direction of self-perception of IBS patients in the context of Iranian culture and belief, encourages the nurses to obtain the necessary knowledge and ability and apply them in development of support programs for such patients.

\section{Material and Methods}

\subsection{Research design and setting}

In order to describe and interpret the lived experience of IBS patients, we used a phenomenological method. Participants were selected among IBS patients referred to three central clinics (two governmental and one private) 
affiliated to Shiraz University of Medical Sciences by purposeful sampling. Inclusion criteria consisted of age over 20 years, at least one year of history of IBS diagnosed by a gastroenterologist based on Rome III criterion (52), speaking fluent Persian, a rich experience of living with the syndrome, willingness to provide complete information to the researcher, and lack of acute cognitive and mental illness and organic disease (e.g. inflammatory bowel disease).

\subsection{Data collection and analysis}

Data were collected from July 2015 through September 2016. In-depth semi-structured interviews and field notes were used to collect data. Generally, 14 interviews with 12 participants were conducted. All interviews were recorded. The duration of each interview was between 40 and 90 minutes. At the beginning of each interview, the participants were asked to explain their experiences about living with IBS. The main questions of the interviews included: "What is it like to live with IBS?", "What does living with IBS mean?", and "What comes to mind when I say IBS?" Gradually the interview continued by asking questions like "Please give me an example" or "Explain more". The recorded interviews were listened to several times, transcribed verbatim, and imported to the MAXQDA software (version 2007) for easy management. The collected data were analyzed based on Van Manen's six-step methodological framework as a guide for interpreting hermeneutics (49) as follows:

2.2.1. Turning to the nature of the lived experience: in this stage, the researcher was interested in understanding the nature of living with IBS at the time of the clinical trial research.

2.2.2. Investigating lived experience: selecting the participants with lived experience with IBS as their integral part was performed at this stage. Participants in their descriptions showed the nature of living with IBS from their personal experiences, and these descriptions were recorded for later written transcription.

2.2.3. Reflecting on the essential themes which characterize the phenomenon: in this stage, using the thematic analysis with selective and holistic technique, there was an attempt to determine the main themes from descriptions of patients from lived experience with IBS. Also, after reflecting on each transcript once while listening to the audio recordings, the themes emerged from the lived experiences with IBS. From the themes, the essence of living with IBS was approached.

2.2.4. Describing the phenomenon through the art of writing and rewriting: the researcher wrote the extracted essential themes from interviews as the story several times for a rich description of lived experience of IBS patients.

2.2.5. Maintaining a strong and oriented relationship with the phenomenon: this phenomenon in this stage was maintained considering the question of "What is the lived experience of IBS patients?"

2.2.6. Balancing the research context by considering the parts and the whole: the researcher maintained the relationship between the parts and the whole in her mind.

Data generation was continued until achieving abstract, related, rich and deep results. Openness was also observed during the study (53).

\subsection{Rigor}

In order to ensure the accuracy of the study, Lincoln and Guba criterion was used (54). For the credibility of the research, the results were presented to participants and they expressed the coordination of results with selfperception during life with IBS. To meet this criterion, the experts' analysis and prolonged engagement were used. By doing some measures like member checking and experts' analysis, the dependability of the study was ensured. By thick and vivid descriptions in the text, effort was made to prepare the background for judgment and evaluation of the others regarding the transferability of the results. Preserving the careful documentations at all stages of the research, and also efforts to obtain the comments of professors of the department of Persian literature, psychiatric nursing and gastroenterologists in this regard helped the confirmability of the research.

\subsection{Ethical considerations}

All ethical issues including description and expression of the purpose of the study and obtaining informed consent for the interview and permission for audio-taping were considered. Performing related coordination for attending the research field, maintaining anonymity and the authority of dissuasion at all stages of the research were also considered. The present study was approved by the Ethics Committee of Shiraz University of Medical Sciences with code No. IR.SUMS.REC.2015. S137.

\section{Results}

In the present study, the participants consisted of 12 Iranian patients ( 7 females and 5 males) with the mean age of 36.5 years and a history of being affected by IBS for between 3-30 years. From the view point of the syndrome type, 4, 3 and 5 participants were affected with constipation, diarrhea and a mixed type respectively. About 2,187 codes 
were obtained according to the overall objective of the original study from the survey of descriptions of participants in the interviews. Around 860 codes related to the concept of "self" regarding the overall objective of the present study were extracted. Finally, the main theme as well as the sub-themes emerged according to Table 1 in the present study. When the participants discussed the lived experience with IBS, they focused on the effect of symptoms on "self", especially at different social situations. One main theme of "different self-perception" and two sub-themes, namely "the threatened self" and "deep self-knowledge" were finally extracted in the present study. IBS lived experience means different self-perception. Participants have had the feeling of threatened-self at some periods of life and sometimes they experienced deep self-knowledge.

Table 1. Theme and its related sub-themes of self-perception experience in IBS patients

\begin{tabular}{|l|l|l|}
\hline Different & Threatened self & Fear from stigmatization \\
\cline { 3 - 3 } & & Bad sense of self \\
\cline { 2 - 3 } & Deep self-knowledge & Body knowledge \\
& & Self-acceptance \\
& & Personal growth \\
\hline
\end{tabular}

\subsection{The threatened self}

One of the dimensions of the concept of patients' self-perception resulted in "the threatened self" from the patients' descriptions. This concept included two sub-themes, namely "fear from stigmatization" and "bad sense of self". Participants experienced feelings of self-assaulting due to the fear of being stigmatized and bad sense of self in their life with IBS.

3.1.1. Fear from stigmatization:

Participants experienced severe fear of real or imaginary incidence of symptoms in the presence of others, fear and refusal of eating in public, feeling ashamed of signs in public, keeping the syndrome secret, and resignation from society. A male participant, 39 years old and married, regarding the fear from the incidence of symptoms stated that: "for example, a class was run in our office and I was afraid all the time, if my stomach starts making noises and...." A woman aged 30 years old and married, regarding the fear of eating and refusing food, expressed: "During life with IBS, I was afraid of eating, especially in public, and that is why I was always deprived of eating many eatables.". A woman aged 40 years and divorced, regarding the feeling of shame and keeping IBS a secret, stated that: "It is difficult for me to go to the bathroom while travelling when it is crowded, because I have not defecated thoroughly, I spend much time in the bathroom and sometimes I feel tenesmus. I usually go to the bathroom early in the morning when everybody is sleeping at the party.". Patients with IBS kept themselves away from society due to the fear of being stigmatized. This concept was inferred from the descriptions of participants, which was an indication of desisting from personal interests, deprivation from social affiliations and restrictions in travelling and occupational opportunities. A 39-year-old woman stated in this regard that: "I gave up lot of things which I loved, I did not pursue further education; I don't go to the classes which I like; living with it (IBS) is too bad; it's painful and I feel comfortable only when I am at home."

3.1.2. Bad sense of "self":

Differentiating self from others, concern regarding others' perceptions of self, feeling of self-disgust and unfavorable image of self-body were obviously reflecting the bad sense of self from the experiences of participants. A 35-year-old married man stated in this connection that: "I have no good feeling in public; I feel weakness and dejected." Also, a married woman aged 36 mentioned that: "I feel differentiated because nobody has this problem but I." As to others' perception of self, a married male participant aged 39 years old stated that: "When my mind is busy with my illness, they ask "why don't you laugh?", "Why are you inconvenienced?", "Why don't you talk?", and "Why are you worried?". Regarding self-disgust, a married man aged 35 years old stated: "wooing memory was so horrible, I had not received a positive answer yet, I had to show myself but I was not feeling well and that's why I hated myself." Some participants had bad sense of self-body. For example, they were worried about their overweight or thinness. Bodily symptoms of the syndrome like dyspareunia, tenesmus, severe stomachache, etc. were among their bad feelings.

\subsection{Deep self-knowledge}

Another dimension of self-perception of the participants was "deep self-knowledge". This theme was extracted from the participants' descriptions and was formed via body knowledge, self-acceptance and personal growth.

3.2.1. Body knowledge:

Body knowledge consisted of accepting the syndrome and dominant body. Some participants described their lived experience with the syndrome indicating that they have accepted the syndrome as a part or a companion in their life 
and have not allowed it to control their life. A single male participant aged 73 years old stated: "One thing is pictured in front of me that I have such problem.... I must compromise with my digestive problem; I must compromise with the discomfort which is inside me..., this means that, I have accepted the syndrome as part of my life." Some participants did not allow the syndrome to reign their life, and resorted to strategies like having sedatives, toilet paper and disposable gloves with them continuously, along with taking herbal and chemical medicines before leaving home to control the symptoms. Specific preparations to defecate at home like personal western toilet and disposable gloves, etc. were also mentioned by the participants.

\subsubsection{Self-acceptance:}

Some participants did not have the feeling of being different from others, and compromised with inability to take everything and even to compromise with the syndrome and self-acceptance; they compared themselves with others suffering from worse diseases. In this regard, a divorced woman aged 40 years old stated that: "I am not like others who for example say that, we love sweets, we wish we could take them. It is not important for me if I cannot eat many things. I just compromise with the way of my eating." A 30-year-old married woman said: "when there is no syndrome, I spend my time for make-up and dressing like healthy people instead of thinking about going to the WC or being worried about stomach noise."

\subsubsection{Personal growth:}

Some participants described personal growth while living with IBS through being appreciated and having a better view of life, compensating for past mistakes, praising God, not causing inconvenience for others and empathizing with peers to compromise with the syndrome. In connection with past mistakes, a married man aged 27 years old explained: "I feel that, I have not appreciated my parents" troubles and I must compensate their favors." Moreover, some participants not only had no inclination of discomforting others, but they were even worried about other's discommodity caused by their illness. A married woman aged 30 years old stated: "We travelled to Isfahan. We had to shorten our trip due to my illness and come back within two days. I was so upset to cause harassment for them." Empathy with peers as the recommendation for the same sufferers to have patience and refer to a physician to start treatment as soon as possible was propounded by the participants. A married man aged 27 years old stated in this regard: "I have learned good things from my illness. Previously, when I heard somebody was sick, I never cared about it, but now I become worried about him/her." Some participants mentioned that, maintaining independency to compromise with IBS is necessary. A married man aged 39 years old stated in this connection: "I could compromise with the syndrome by proper diet, reducing stress and maintaining peace in my life. I have reached this position by joining positive groups and I read their subjects. This is not a type of illness which somebody can help. I must try myself."

\section{Discussion}

This qualitative study focused on the self-perception of Iranian patients during life with IBS which is a part of the results of the main project of IBS patients' lived experience. The results of the present study showed that, these patients experienced both threatened self as well as deep self-knowledge. The theme "threatened self" consisted of two sub-themes of "fear from stigmatization" and "bad sense of self". Fear from stigmatization refers to the fact that, IBS patients experience severe anxiety and fear in the presence of others. They also have fear and refuse to eat in public and hide their IBS from others. On the other hand, due to living with IBS, they have forgone many of their interests, occupational opportunities and social situations and somehow, they prefer staying-at-home to carry out social affairs; they in fact experience social resignation. In this regard, Ronnevig et al., in a phenomenology study, reported the narratives of 13 Norwegian patients with IBS on the subject of fear and shame of symptoms in public (44). Also, the results of a study in this regard was similar to the present research (55). The emergence of the theme "feeling ashamed" due to the negative and taboo symptoms in a phenomenology research carried out by Hakanson et al. via interviews with Swedish patients also confirmed the results of the present study (45). Drossman et al., in a qualitative study as a focus group, reported the feeling of fear, embarrassment and shame, limitation in activities and social relations, and the stigma caused due to the lack of understanding by others (47). Also, Canadian patients, in their interviews in a phenomenology study, mentioned the embarrassment from emotional effects and the stigma due to leaving the workplace during an attack of IBS (46). Obviously, the themes emerged from the interviews with Iranian participants in the present study are similar to the themes obtained from the patient's descriptions of developed countries. Hence, the themes are universal. "Bad sense of self" was the other sub-theme related to the threatened self theme. Differentiating self from others, being concerned about the others' imaginations of self, feeling self-disgusted and having unfavorable mental image of self body sub-sub-themes are related to the bad sense of self. In a phenomenology study carried out by Hakanson et al., the feeling of mental and bodily difference with others and feeling disgust, which are among the negative and taboo symptoms in the remarks of Swedish patients with IBS, confirm the results of the present study (45). Painful feeling of being different from others in a qualitative 
research carried out by McCormick et al. in the USA on IBS patients and inflammatory bowel disease (IBD) as a focus group (56), confirmed the results of our study. The "self" in health and illness is a complex, plural and dynamic phenomenon that can be, in turn, private (intra-personal), social (inter-personal) (57) and rooted over the course of time (58). In the present study also, the theme "threatened self" was formed from the intra-personal and inter-personal sub-themes. Therefore, it is clear that, self-sentiment would be reflected throughout all his/her attitudes. The theme "deep self-knowledge" was formed from the sub-themes of body knowledge, self-acceptance and personal growth. In this regard, in a phenomenology research carried out by Jakobsson et al., self-centeredness and disciplined self-care were extracted from the interviews of Swedish patients with IBS (43). Also, the theme "self-fulfillment" emerged in a qualitative research with the thematic content analysis method which showed the perception of Swedish women with IBS regarding good quality of life (50). While working with patients with emotional distress, Carl Rogers a psychologist, phenomenologist and humanist stated in his theory that humanbeings have a significant capacity for self-healing, personal growth and thus self-actualization (39). In this connection, Farndale and Roberts carried out a qualitative research on the long-term effect of IBS on the quality of life of German patients using thematic analysis method. The integration of the syndrome in life and becoming part of an identity were among the results of this study (59) that have similarity with those of the present study. On the other hand, redefinition of self was among the themes that Sharpe et al. reported with sub-themes such as pain as a part of the whole self, and making an effort for self-acceptance as expressed by Canadian women who were living with chronic pain (60). In another qualitative study in Canada on conceptualization of self-concept of women with osteoporosis, the theme of strong sense of self-confidence permitted women to protect the boundaries between selfconcept and negative ideas about chronic illness (61). Hellstrom, in a qualitative study, focused on the temporal dimensions of self-concept among patients with chronic pain (58). He referred to the research of Cross and Markus regarding the conceptualization of possible selves as psychological resources which are instrumental in adapting to new roles across the life span (62). He also pointed that possible selves in this span can be considered as resources in adapting chronic pain and be motivators for health behavior (58). These results are similar to those of the present study in such a way that the participants can prepare a resource for adapting with the syndrome during life with IBS and obtaining deep self-knowledge. Terms like self-concept, sense of self and identity are often used interchangeably (63). Also, one's self-perception is defined by one's self-concept, self-knowledge, self-esteem and social self (40). Therefore, the participants of the present study, during their life with IBS, had experience of threatened self as fear of being stigmatized due to bodily symptoms of syndrome and bad sense of self in some days and moments. Sometimes, also through attention to self, body and the syndrome and in fact body-knowledge, selfacceptance and personal growth and finally reaching deep self-knowledge, the patients specified another dimension of the definition of patients' self-perception or the same identity or, in other words, self-concept. In fact, living with IBS has caused these patients to have the feeling of threatened identity and deep recognition of their identity at various periods of time. "Self in IBS person will be threatened via perception of individual from others about his/her, self-disgust and unfavorable image of self. On the other hand, IBS person attains deep self-knowledge throughout considering the syndrome as the part of his/her life, listening to the body tone, being marked and not creating discommodity for others. Different self-perception was the new theme produced from this study which is not seen in other studies. As a whole, "self" will be the final goal of an IBS patient. Although lack of generalizability of the results of qualitative research is the characteristic of such studies, it may be considered as one of the limitations of this type of research from the view point of those who give great importance to practical use of the results of research.

\section{Conclusions}

The results of the present study can be used to design and implement the effective care for patients with IBS considering the domains of nursing management, education and research. The results of this research could also open the way for other studies in this connection focusing on the literature reviews surveyed so far. To the best of our knowledge, this study is the first qualitative research in this regard in Iran. It is suggested that the future studies survey the experiences of nurses, physicians and families of such patients so as to obtain deeper insight regarding IBS. It is hoped that using the obtained knowledge at the direction of self-perception of IBS patients in the context of Iranian culture and belief, encourages the nurses to obtain the necessary knowledge and ability and apply them in the development of support programs for such patients.

\section{Acknowledgments:}

The current study is the result of a part of a Ph.D. dissertation in nursing, Approved Project No. 94-7505. We hereby appreciate the Research Vice-chancellor of Shiraz University of Medical Sciences who supported us financially, and also, all participants and those who helped us to carry out this study. The authors would like to thank Shiraz 
University of Medical Sciences, Shiraz, Iran and also the Center for Development of Clinical Research of Nemazee Hospital and Dr. Nasrin Shokrpour for editorial assistance.

\section{Conflict of Interest:}

There is no conflict of interest to be declared.

\section{Authors' contributions:}

All authors contributed to this project and article equally. All authors read and approved the final manuscript.

\section{References:}

1) Wald A. Irritable bowel syndrome--diarrhoea. Best Pract Res Clin Gastroenterol. 2012; 26(5): 573-80. doi: 10.1016/j.bpg.2012.11.002. PMID: 23384803.

2) Scalera A, Loguercio C. Focus on irritable bowel syndrome. Eur Rev Med Pharmacol Sci. 2012; 16(9): 1155-71. PMID: 23047498.

3) Hinkle JL, Cheever KH. Brunner \& Suddarth's Textbook of Medical-Surgical Nursing, 13th ed. Lippincott Williams \& Wilkins; 2014.

4) Spiegel BM. The burden of IBS: looking at metrics. Curr Gastroenterol Rep. 2009; 11(4): 265-9. doi: 10.1007/s11894-009-0039-x. PMID: 19615301.

5) Koloski NA, Jones M, Kalantar J, Weltman M, Zaguirre J, Talley N. The brain-gut pathway in functional gastrointestinal disorders is bidirectional: a 12-year prospective population-based study. Gut. 2012; 61(9): 1284-90. doi: 10.1136/gutjnl-2011-300474. PMID: 22234979.

6) Jahangiri P, Jazi MS, Keshteli AH, Sadeghpour S, Amini E, Adibi P. Irritable Bowel Syndrome in Iran: SEPAHAN Systematic Review No. 1. Int J Prev Med. 2012; 3(Suppl 1): S1-9. PMID: 22826748, PMCID: PMC3399304.

7) Khademolhosseini F, Mehrabani D, Nejabat M, Beheshti M, Heydari ST, Mirahmadizadeh A, et al. Irritable bowel syndrome in adults over 35 years in Shiraz, southern Iran: prevalence and associated factors. J Res Med Sci. 2011; 16(2): 200-6. PMID: 22091232, PMCID: PMC3214304.

8) Sperber AD, Dumitrascu D, Fukudo S, Gerson C, Ghoshal UC, Gwee KA, et al. The global prevalence of IBS in adults remains elusive due to the heterogeneity of studies: a Rome Foundation working team literature review. Gut. 2017; 66(6): 1075-82. doi: 10.1136/gutjnl-2015-311240. PMID: 26818616.

9) Nabolsi M. Psychosomatic principles and classifications. Elhelal for publishing Amman, Jordan. 1994.

10) North CS, Downs D, Clouse RE, Alrakawi A, Dokucu ME, Cox J, et al. The presentation of irritable bowel syndrome in the context of somatization disorder. Clin Gastroenterol Hepatol. 2004; 2(9): 787-95. doi: 10.1016/S1542-3565(04)00350-7. PMID: 15354279.

11) Boyd C, Abraham S, Kellow J. Psychological features are important predictors of functional gastrointestinal disorders in patients with eating disorders. Scand J Gastroenterol. 2005; 40(8): 929-35. doi: 10.1080/00365520510015836. PMID: 16170899.

12) Modabbernia MJ, Mansour-Ghanaei F, Imani A, Mirsafa-Moghaddam SA, Sedigh-Rahimabadi M, Yousefi-Mashhour M, et al. Anxiety-depressive disorders among irritable bowel syndrome patients in Guilan, Iran. BMC Res Notes. 2012; 5: 112. doi: 10.1186/1756-0500-5-112. PMID: 22353390, PMCID: PMC3392738.

13) Farzaneh N, Ghobakhlou M, Moghimi-Dehkordi B, Naderi N, FadaiF. Anxiety and depression in a sample of Iranian patients with irritable bowel syndrome. Iran J Psychiatry Behave Sci. 2013; 7(1): 30-6. PMID: 24644497, PMCID: PMC3939983.

14) Tamannaifar MR, Akhavan-Hejazi Z. Comparing the mental health and quality of life in patients with irritable bowel syndrome and healthy subjects in Kashan, Iran. Feyz. 2013; 17(2): 195-202.

15) Drossman DA, Camilleri M, Mayer EA, Whitehead WE. AGA technical review on irritable bowel syndrome. Gastroenterology. 2002; 123(6): 2108-31. doi: 10.1053/gast.2002.37095. PMID: 12454866.

16) Bengtsson M, Sjöberg K, Candamio M, Lerman A, Ohlsson B. Anxiety in close relationships is higher and self-esteem lower in patients with irritable bowel syndrome compared to patients with inflammatory bowel disease. Eur J Intern Med. 2013; 24(3): 266-72. doi: 10.1016/j.ejim.2012.11.011. PMID: 23245929.

17) Halder SL, Locke GR 3rd, Talley NJ, Fett SL, Zinsmeister AR, Melton LJ 3rd. Impact of functional gastrointestinal disorders on health-related quality of life: a population-based case-control study. Aliment Pharmacol Ther. 2004; 19(2): 233-42. doi: 10.1111/j.0269-2813.2004.01807.x. PMID: 14723614.

18) Cain KC, Headstrom P, Jarrett ME, Motzer SA, Park H, Burr RL, et al. Abdominal pain impacts quality of life in women with irritable bowel syndrome. Am J Gastroenterol. 2006; 101(1): 124-32. doi: 10.1111/j.1572-0241.2006.00404.x. PMID: 16405544. 
19) Minocha A, Johnson WD, Abell TL, Wigington WC. Prevalence, sociodemography, and quality of life of older versus younger patients with irritable bowel syndrome: a population-based study. Dig Dis Sci. 2006; 51(3): 446-53. doi: 10.1007/s10620-006-3153-8. PMID: 16614950.

20) Li FX, Patten SB, Hilsden RJ, Sutherland LR. Irritable bowel syndrome and health-related quality of life: a population-based study in Calgary, Alberta. Can J Gastroenterol. 2003; 17(4): 259-63. doi: 10.1155/2003/706891. PMID: 12704470.

21) Blanchard EB, Scharff L. Psychosocial aspects of assessment and treatment of irritable bowel syndrome in adults and recurrent abdominal pain in children. J Consult Clin Psychol. 2002; 70(3): 725-38. doi: 10.1037/0022-006X.70.3.725. PMID: 12090379.

22) Levy RL, Olden KW, Naliboff BD, Bradley LA, Francisconi C, Drossman DA, et al. Psychosocial aspects of the functional gastrointestinal disorders. Gastroenterology. 2006; 130(5): 1447-58. doi: 10.1053/j.gastro.2005.11.057. PMID: 16678558.

23) Grodzinsky E, Walter S, Viktorsson L, Carlsson AK, Jones MP, Faresjö Å. More negative self-esteem and inferior coping strategies among patients diagnosed with IBS compared with patients without IBS--a casecontrol study in primary care. BMC Fam Pract. 2015; 16: 6. doi: 10.1186/s12875-015-0225-x. PMID: 25626450, PMCID: PMC4316793.

24) Canavan C, West J, Card T. The epidemiology of irritable bowel syndrome. Clin Epidemiol. 2014; 6: 71 80. doi: 10.2147/CLEP.S40245. PMID: 24523597, PMCID: PMC3921083.

25) Longstreth GF, Wilson A, Knight K, Wong J, Chiou CF, Barghout V, et al. Irritable bowel syndrome, health care use, and costs: a US managed care perspective. Am J Gastroenterol. 2003; 98(3): 600-7. doi: 10.1111/j.1572-0241.2003.07296.x. PMID: 12650794.

26) Riddle MS, Welsh M, Porter CK, Nieh C, Boyko EJ, Gackstetter G, et al. The Epidemiology of Irritable Bowel Syndrome in the US Military: Findings from the Millennium Cohort Study. Am J Gastroenterol. 2016; 111(1): 93-104. doi: 10.1038/ajg.2015.386. PMID: 26729548. PMCID: PMC4759150.

27) Nellesen D, Yee K, Chawla A, Lewis BE, Carson RT. A systematic review of the economic and humanistic burden of illness in irritable bowel syndrome and chronic constipation. J Manag Care Pharm. 2013; 19: 755-64. doi: 10.18553/jmcp.2013.19.9.755. PMID: 24156644.

28) Moghimi-Dehkordi B, Vahedi M, Pourhoseingholi MA, Khoshkrood Mansoori B, Safaee A, Habibi M, et al. Economic burden attributable to functional bowel disorders in Iran: A cross - sectional population based study. J Dig Dis. 2011; 12(5): 384-92. doi: 10.1111/j.1751-2980.2011.00526.x. PMID: 21955432.

29) McFarland LV. State-of-the-art of irritable bowel syndrome and inflammatory bowel disease research in 2008. World J Gastroenterol. 2008; 14(17): 2625-9. doi: 10.3748/wjg.14.2625. PMID: 18461647, PMCID: PMC2709056.

30) Drossman DA, Whitehead WE, Camilleri M. Irritable bowel syndrome: a technical review for practice guideline development. Gastroenterology. 1997; 112(6): 2120-37. doi: 10.1053/gast.1997.v112.agast972120. PMID: 9178709.

31) Thompson WG. The treatment of irritable bowel syndrome. Aliment Pharmacol Ther. 2002; 16(8): 1395406. doi: 10.1046/j.1365-2036.2002.01312.x. PMID: 12182740.

32) Whitehead WE, Levy R, Von Korff M, Feld AD, Palsson OS, Turner M, et al. The usual medical care for irritable bowel syndrome. Aliment Pharmacol Ther. 2004; 20(11 - 12): 1305-15. doi: 10.1111/j.13652036.2004.02256.x. PMID: 15606392.

33) Ferreira NB, Eugenicos M, Morris PG, Gillanders D. Using acceptance and commitment therapy in irritable bowel syndrome. Gastrointestinal Nursing. 2011; 9(9): 28-35. doi: 10.12968/gasn.2011.9.9.28.

34) Asadi M, Fayazi S, Adarvishi S, Alavinejad P, Latifi M, Soleimani A. The Effect of Benson Relaxation on Quality of Life of Patients with Irritable Bowel Syndrome. Jundishapur Journal of Chronic Disease Care. 2016; 5(4): 1-9. doi: 10.17795/jjcdc-31068.

35) Shahbazi K, Solati K, Hasanpour-Dehkordi A. Comparison of Hypnotherapy and Standard Medical Treatment Alone on Quality of Life in Patients with Irritable Bowel Syndrome: A Randomized Control Trial. J Clin Diagn Res. 2016; 10(5): OC01-4. doi: 10.7860/JCDR/2016/17631.7713. PMID: 27437261, PMCID: PMC4948437.

36) Tanaka Y, Kanazawa M, Fukudo S, Drossman DA. Biopsychosocial model of irritable bowel syndrome. J Neurogastroenterol Motil. 2011; 17(2): 131-9. doi: 10.5056/jnm.2011.17.2.131. PMID: 21602989, PMCID: PMC3093004.

37) Charmaz K. The self as habit: The reconstruction of self in chronic illness. OTJR: Occupation, Participation and Health. 2002; 22(1 suppl): 31S-41. doi: 10.1177/15394492020220S105.

38) Wylie RC. The self-concept: Theory and research on selected topics: U of Nebraska Press; 1974. 
39) Rogers CR, Koch S. A theory of therapy, personality, and interpersonal relationships: as developed in the client-centered framework. 1959.

40) Myers DG. Social psychology New York: McGraw-Hill Higher; 2009.

41) Bhattacharjee A. Self concept of cancer patients: a comparative study. Voice of Research. 2013; 1(4): 2277-7733.

42) Franken R. Human motivation (3rd ed). Pacific Grove, CA: Brooks/Cole; 1994.

43) Ung EJ, Ringstrom G, Sjövall H, Simrén M. How patients with long-term experience of living with irritable bowel syndrome manage illness in daily life: a qualitative study. European journal of gastroenterology \& hepatology. 2013; 25(12): 1478-83. doi: 10.1097/MEG.0b013e328365abd3. PMID: 24047860.

44) Rønnevig M, Vandvik PO, Bergbom I. Patients' experiences of living with irritable bowel syndrome. J Adv Nurs. 2009; 65(8): 1676-85. doi: 10.1111/j.1365-2648.2009.05030.x. PMID: 19493148.

45) Håkanson C, Sahlberg - Blom E, Nyhlin H, Ternestedt BM. Struggling with an unfamiliar and unreliable body: the experience of irritable bowel syndrome. Journal of Nursing and Healthcare of Chronic Illness. 2009; 1(1): 29-38. doi: 10.1111/j.1365-2702.2008.01001.x.

46) Schneider MA, Fletcher PC. 'I feel as if my IBS is keeping me hostage!' Exploring the negative impact of irritable bowel syndrome (IBS) and inflammatory bowel disease (IBD) upon university - aged women. Int J Nurs Pract. 2008; 14(2): 135-48. doi: 10.1111/j.1440-172X.2008.00677.x. PMID: 18315827.

47) Drossman DA, Chang L, Schneck S, Blackman C, Norton WF, Norton NJ. A focus group assessment of patient perspectives on irritable bowel syndrome and illness severity. Dig Dis Sci. 2009; 54(7): 1532-41. doi: 10.1007/s10620-009-0792-6. PMID: 19337833.

48) Widmark-Petersson V, von Essen L, Sjödén PO. Perceptions of caring among patients with cancer and their staff: Differences and disagreements. Cancer Nurs. 2000; 23(1): 32-9. doi: 10.1097/00002820200002000-00005. PMID: 10673805.

49) Van Manen M. Researching lived experience: Human science for an action sensitive pedagogy. New York, NY: State University of New York Press; 1990.

50) Bengtsson M, Ohlsson B, Ulander K. Women with irritable bowel syndrome and their perception of a good quality of life. Gastroenterol Nurs. 2007; 30(2): 74-82. doi: 10.1097/01.SGA.0000267924.24180.1a.

51) Falvo D. Medical and psychosocial aspects of chronic illness and disability. Jones \& Bartlett Publishers; 2013.

52) Drossman DA. The functional gastrointestinal disorders and the Rome III process. Gastroenterology. 2006; 130(5): 1377-90. doi: 10.1053/j.gastro.2006.03.008. PMID: 16678553.

53) Van Manen M. Phenomenology of practice: Meaning-giving methods in phenomenological research and writing: Routledge; 2014.

54) Lincoln YS, Guba EG. Naturalist enquiry. Los Angles: Sage Publications; 1985.

55) Taft TH, Riehl ME, Dowjotas KL, Keefer L. Moving beyond perceptions: internalized stigma in the irritable bowel syndrome. Neurogastroenterol Motil. 2014; 26(7): 1026-35. doi: 10.1111/nmo.12357. PMID: 24832499.

56) McCormick JB, Hammer RR, Farrell RM, Geller G, James KM, Loftus EV, et al. Experiences of patients with chronic gastrointestinal conditions: in their own words. Health Qual Life Outcomes. 2012; 10: 25. doi: 10.1186/1477-7525-10-25. PMID: 22401607, PMCID: PMC3349594.

57) Contrada RJ, Ashmore RD. Self, social identity, and physical health: Interdisciplinary explorations. Oxford University Press; 1999.

58) Hellström C. Temporal dimensions of the self-concept: Entrapped and possible selves in chronic pain. Psychology and Health. 2001; 16(1): 111-24. doi: 10.1080/08870440108405493.

59) Farndale R, Roberts L. Long-term impact of irritable bowel syndrome: a qualitative study. Prim Health Care Res Dev. 2011; 12(1): 52-67. doi: 10.1017/S1463423610000095. PMID: 21426615.

60) Sharpe H, Alderson K, Collins S. An Exploration of Positive Identity Development in Women Living with Chronic Pain. The Qualitative Report. 2013; 18(Art29): 1-22.

61) Wilkins S. Aging, chronic illness and self-concept: A study of women with osteoporosis. J Women Aging. 2001; 13(1): 73-92. doi: 10.1300/J074v13n01-06. PMID: 11217187.

62) Cross S, Markus H. Possible selves across the life span. Human development. 1991; 34(4): 230-55. doi: $10.1159 / 000277058$.

63) Osborn M, Smith JA. Living with a body separate from the self. The experience of the body in chronic benign low back pain: an interpretative phenomenological analysis. Scand J Caring Sci. 2006; 20(2): 21622. doi: 10.1111/j.1471-6712.2006.00399.x. PMID: 16756528. 